\title{
Chronic kidney disease in primary care
}

\author{
Prabir Kumar Mitra ${ }^{1} \quad$ John R Bradley²
}

J R Soc Med 2007; 100:40-45

\section{SUMMARY}

It has been estimated that chronic kidney disease (CKD) affects about one in 200 of the population in the UK. There is an increased awareness of the need to identify patients in primary care with CKD at an earlier stage, so that treatments can be initiated to delay progression and prevent complications and appropriate nephrological referral can be made. In this article we will review how measures to identify patients with CKD can improve its management.

\section{INTRODUCTION}

\section{Prevalence of chronic kidney disease}

Chronic kidney disease (CKD) is under-diagnosed and under-treated. Part two of the National Service Framework for Renal Services focuses on CKD and its identification and management in primary care to minimize its consequences. The true prevalence of CKD in the population, and hence its social and economic burden, is unknown. A survey of blood samples in the south east of England in 2000/2001 (using creatinine cut offs of $180 \mu \mathrm{mol} / \mathrm{L}$ in men and $135 \mu \mathrm{mol} / \mathrm{L}$ in women, as recommended by the US National Institute of Health) found the prevalence of diagnosed CKD (median glomerular filtration rate $28.5 \mathrm{~mL} / \mathrm{min}$ ) to be 5540 per million population. ${ }^{1}$

Established renal failure requiring treatment with dialysis is increasing, but remains relatively rare. In 2002, 19307 adults were receiving dialysis in the UK, an increase of $20 \%$ on the number from the National Renal Survey in $1998 .^{2}$ The treatment is expensive, however, costing over $2 \%$ of the NHS budget.

\section{Benefits of early detection}

There is an increased awareness of the need to identify patients with CKD at an earlier stage, so that appropriate treatment can be initiated to delay progression and prevent complications of established renal failure, including anaemia and renal bone disease. CKD is well established as a predictor of cardiovascular mortality, but kidney dysfunction

${ }^{1}$ St James Medical Practice, King's Lynn, Norfolk PE30 4ET, UK

E mail: mitra_prabir@yahoo.co.uk

${ }^{2}$ Cambridge University Hospitals NHS Foundation Trust, Cambridge CB2 2QQ, UK has recently been shown to predict non-cardiovascular mortality from multiple causes in the elderly. ${ }^{3}$ Deaths attributed to pulmonary disease, infection, cancer and other causes have all been associated with high levels of cystatin $\mathrm{C}$, an endogenous marker of glomerular filtration rate that is not dependent on muscle mass.

Guidelines for the identification, management and referral of patients with CKD have recently been published. ${ }^{4}$ In its early stages the management of CKD requires specialist knowledge, which can often be delivered in either primary or secondary care. Technical expertise available only in secondary care is required at a later stage to prepare for and provide renal replacement therapy. Patients who are likely to require dialysis benefit from early referral to a nephrologist.

In a recent survey of a single general practice in eastern England we found that the majority of patients with CKD do not undergo regular monitoring of their renal function or related parameters to enable appropriate management of the progression and complications of renal disease. 3.7\% of patients had been found to have a serum creatinine $>120$ $\mu \mathrm{mol} / \mathrm{L}$ during the previous three years, but only $1.7 \%$ had serum creatinine measured over a period of more than three months, thereby meeting the criteria for CKD.

\section{METHODS}

A literature review using the medical databases Medline, Embase and Cochrane was undertaken, and guidelines from the Renal Association in the UK and National Kidney Foundation in US were reviewed, to identify recommendations regarding management of patients with CKD relevant to primary care. After a literature search using the keywords 'chronic kidney disease', 'primary care', 'pre dialysis', 'management' and 'guideline', a review of guidelines, and networking with several experts, a number of proposals relating to the identification, management and referral of patients with CKD are presented and discussed.

\section{IDENTIFICATION AND CLASSIFICATION OF CKD}

\section{Estimating glomerular filtration rate}

The most widely used measures of glomerular filtration rate have been serum creatinine concentration or creatinine clearance, calculated from the amount of creatinine in a 24-hour urine collection and a single measurement during 
this time of blood creatinine, which is assumed to be stable throughout the period of urine collection. Creatinine clearance tends to over-estimate glomerular filtration rate because creatinine is secreted by tubules as well as being filtered by the glomerulus, but - of more importancemeasurement of creatinine clearance involves timed collections of urine, which are inconvenient and often incomplete. Although serum creatinine is widely used as an estimate of renal function, it is unreliable because it is secreted by renal tubules and affected by a number of parameters, in particular muscle mass. A better estimate of glomerular filtration rate can be obtained without resorting to 24-hour urine collection or nuclear medicine by using formulae such as the Cockcroft-Gault equation.

The Modification of Diet in Renal Disease (MDRD) equation, which takes into account serum creatinine, age, gender, race and body mass, provides a more accurate estimate glomerular filtration rate from serum creatinine. ${ }^{5}$ Kidney Disease: Improving Global Outcomes (KDIGO) has defined CKD as kidney damage or glomerular filtration rate $<60 \mathrm{~mL} / \mathrm{min} / 1.73 \mathrm{~m}^{2}$ for three months or more, irrespective of cause. ${ }^{6}$ Kidney damage in many kidney diseases can also be ascertained by the presence of albuminuria, which can be detected by urinalysis and confirmed by finding albumin-to-creatinine ratio $>30 \mathrm{mg} / \mathrm{g}$ in two of three spot urine specimens. ${ }^{6}$ Kidney disease severity has been classified into five stages according to the level of glomerular filtration rate (Table 1) and the presence of abnormalities on urinalysis. Classification is important because it is a predictor of the likelihood of both complications and progression, and so provides a guide to the need for further investigations, follow up and nephrological referral.

\section{When to refer from primary to secondary care}

The UK CKD Guidelines ${ }^{4}$ are particularly useful in advising when to refer patients to a nephrologist. The guide recommends that patients with stage 4 or 5 CKD should be referred, whereas patients with stage 3 CKD require referral if there is progressive fall in glomerular filtration rate or rise in serum creatinine, microscopic haematuria, proteinuria if urine protein-creatinine ratio is $>100 \mathrm{mg} /$ mmol, unexplained anaemia, abnormal potassium, calcium or phosphate, a suspected systemic illness, or uncontrolled blood pressure $>150 / 90 \mathrm{mmHg}$ on three agents. In patients with CKD, the result of urine dipstick analysis is always informative. In the absence of infection, microscopic haematuria in the presence of proteinuria or raised creatinine usually signifies renal disease. Proteinuria can be readily quantified by measuring urine protein-creatinine ratios. Unlike haematuria, proteinuria almost always has a renal origin, and levels in excess of $100 \mathrm{mg} / \mathrm{mmol}$ usually indicate glomerular disease.

\section{PREVENTING PROGRESSION OF CKD}

\section{Establishing the cause}

CKD occurs largely in the elderly, and is also more prevalent in many ethnic minority groups. Common causes of CKD are diabetic nephropathy, hypertension and renovascular disease, glomerulonephritis, interstitial nephritis due to reflux nephropathy (often termed pyelonephritis), polycystic kidney disease, obstructive uropathy. In about a quarter of patients receiving renal replacement therapy in the UK the cause of the underlying renal disease is unknown. Glomerulonephritis, which is twice as common in men, and pyleonephritis are the most common causes of kidney disease in patients under 65 receiving renal replacement therapy, whereas diabetes, hypertension and renovascular disease are more common in elderly males. ${ }^{7}$ Establishing the cause, which usually requires imaging and may require renal biopsy, is important because in some cases treating the primary disease prevents kidney damage.

Table 1 Classification of CKD by severity ${ }^{6}$

\begin{tabular}{|c|c|c|c|}
\hline $\begin{array}{l}\text { Stages } \\
\text { of CKD }\end{array}$ & Description & $\begin{array}{l}\text { GFR } \\
\left(\mathrm{mL} / \mathrm{min} / 1.73 \mathrm{~m}^{2}\right)\end{array}$ & Related terms \\
\hline 1 & $\begin{array}{l}\text { Kidney damage with normal or } \uparrow \text { glomerular } \\
\text { filtration rate }\end{array}$ & $>90$ & Albuminuria, proteinuria, haematuria \\
\hline 2 & Kidney damage with mild $\downarrow$ glomerular filtration rate & $60-89$ & Albuminuria, proteinuria, haematuria \\
\hline 3 & Moderate $\downarrow$ glomerular filtration rate & $30-59$ & Chronic renal insufficiency, early renal insufficiency \\
\hline 4 & Severe $\downarrow$ glomerular filtration rate & $15-29$ & $\begin{array}{l}\text { Chronic renal insufficiency, late renal insufficiency, } \\
\text { pre-end stage renal disease }\end{array}$ \\
\hline 5 & Kidney failure & $<15$ or dialysis & Renal failure, uraemia, end stage renal disease \\
\hline
\end{tabular}

The criteria for the definition of CKD are either kidney damage or glomerular filtration rate $<60 \mathrm{~mL} / \mathrm{min}$ for $\geqslant 3$ months. Kidney damage is defined as pathological abnormalities or markers of damage, including abnormalities in blood or urine tests or imaging studies. CKD, chronic kidney disease; GFR, glomerular filtration rate 
Even when there is no specific treatment for the underlying cause, control of blood pressure and reduction of proteinuria can prevent deterioration in renal function. Proteinuria predicts progression to end stage renal disease, and if proteinuria is decreased progression to end stage renal failure is reduced. Drugs that counteract the action of angiotensin II lower proteinuria, and slow the rate of disease progression in both diabetic and non-diabetic renal disease ${ }^{8}$ The role of dietary protein restriction is less clear, with little benefit being achieved in the Modification of Diet in Renal Disease Study. ${ }^{9}$ The Study of Heart and Renal Protection (SHARP) should define the role of lipid lowering therapy in CKD. ${ }^{10}$

\section{MANAGEMENT OF COMPLICATIONS}

Treatment with recombinant human erythropoietin $(\mathrm{rHu}$ EPO) in CKD corrects anaemia, avoids the requirement for blood transfusions and also improves quality of life and exercise capacity. ${ }^{11}$ Treatment of absolute or functional iron deficiency is required to maximize erythropoeisis, and intravenous iron may be needed. The management of renal anaemia in the UK is usually co-ordinated by specialist nurses, often using policies for shared primary and secondary care in the assessment, prescribing and monitoring of treatment.

The management of bone disease in CKD is complex and rapidly evolving as new treatments to control calcium, phosphate and parathyroid hormone levels become available. Phosphate retention, reduced 1,25-dihydroxycholecalciferol and secondary hyperplasia of the parathyroid glands all contribute to bone disease, and may adversely affect other organs. There is particular concern over the role of disturbed mineral metabolism in soft tissue, and in particular vascular calcification. Calcium, phosphorus and intact plasma parathyroid hormone (PTH) should be measured in all patients with CKD and glomerular filtration rate $<60 \mathrm{~mL} / \mathrm{min} / 1.73 \mathrm{~m}^{2}$, and guidelines concerning target levels in different stages of renal disease have been produced (Table 2). ${ }^{12}$ Measures to control phosphate levels include dietary restriction and oral phosphate binders. Sevelamer, and in the future lanthanum, offer phosphate

Table 2 Target levels of 'intact' parathyroid hormone in different stages of $\mathrm{CKD}^{12}$

\begin{tabular}{lll}
\hline $\begin{array}{l}\text { Stage of } \\
\boldsymbol{C K D}\end{array}$ & GFR $\left(\mathbf{m L} / \mathbf{m i n} / \mathbf{1 . 7 3 \mathbf { m } ^ { 2 } )}\right.$ & $\begin{array}{l}\text { Target 'intact' parathyroid } \\
\text { hormone }(\mathbf{p g} / \mathbf{m L}) \text { [pmol/L] }\end{array}$ \\
\hline 3 & $30-59$ & $35-70[3.85-7.7 \mathrm{pmol} / \mathrm{l}]$ \\
4 & $15-29$ & $70-110[7.7-12.1 \mathrm{pmol} / \mathrm{l}]$ \\
5 & $<15$ or dialysis & $150-300[16.5-33.0 \mathrm{pmol} / \mathrm{l}]$
\end{tabular}

CKD, chronic kidney disease; GFR, glomerular filtration rate control without the problems associated with aluminum- or calcium-based phosphate binders. Active vitamin D compounds can be used to treat vitamin D deficiency and suppress hyperparathyroidism, and newer vitamin D metabolites, including 22-oxacalcitriol, paricalcitol and doxercalciferol, may suppress parathyroid hormone with less effect on plasma calcium. Calcimimetics modulate the calcium sensing receptor in parathyroid and other cells, and can simultaneously reduce calcium, phosphate and Parathormone. If medical treatment to suppress hyperparathyroidism fails parathyroidectomy may be necessary.

\section{PREPARING FOR DIALYSIS}

Late referral has often been defined as referral of a patient with progressive kidney failure from primary to secondary care less than three months before the need to start dialysis. ${ }^{13}$ About one third of patients are referred to a nephrologist at a late stage of renal disease, and this is associated with a poorer state at the start of dialysis, a worse outcome, and higher health care costs. All patients with a progressive increase in serum creatinine level need referral to a nephrologist, and preparation for renal replacement therapy ideally requires frequent contact with a renal team over at least a year.

Appropriate management of CKD therefore involves identifying and treating reversible causes of renal failure, slowing the progressive decline in renal function that typically occurs, and managing the complications associated with CKD. Although these aspects of renal disease can be managed in primary or secondary care, facilitating entry into renal replacement therapy programs for all patients who might benefit requires involvement of the multidisciplinary team available in secondary care. CKD must be identified at an early stage, so that appropriate treatment can be initiated and the need for nephrological referral assessed.

\section{CONCLUSION AND RECOMMENDATIONS}

The general population prevalence ${ }^{14}$ of CKD stages $3-5$ has been estimated at $5.1 \%$, but there is evidence to suggest that a large number of patients with CKD, particularly those in the early stages, are under-diagnosed. Furthermore, the majority of patients with CKD may not undergo regular monitoring of their renal function or related parameters to enable appropriate management of the progression and complications of renal disease. CKD has been included in this year's General Medical Services contract for general practitioners, and following the work of the UK CKD Guidelines Group, the National Institute for Health and Clinical Excellence plans to develop a clinical guideline on the early identification, early management and timely referral of adult patients with CKD in primary and secondary care. A proposed 
Who to monitor

Patients with:

- eGFR $<60 \mathrm{ml} / \mathrm{min}$

- Cardiovascular disease (CVD)

- Diabetes

- Hypertension

- Obstructive uropathy \& neurogenic bladder

- Specific medications

- Multisystem disease-SLE, Vasculitis, Myeloma, RA

- Parenchymal kidney disease

- Referral from secondary care - e.g.

Recovering from ARF, pre-dialysis patients, etc

- Urinary stone disease / Urinary diversion surgery
CVD: Coronary Artery disease, Cerebrovascular disease, Renal artery stenosis, Peripheral vascular disease, Congestive Heart Failure, Left ventricular hypertrophy

Specific Medications: Diuretics, ACE inhibitors, AR Blockers,

Parenchymal Kidney Disease: polycystic kidney disease, chronic glomerulonephritis, and reflux nephropathy

\section{What to monitor}

- Blood pressure - during each review

- Bloods:

\section{Haemoglobin}

2. Creatinine \& eGFR

3. $\mathrm{Na}^{+}, \mathrm{K}^{+}$

4. $\mathrm{Ca}^{+2}, \mathrm{PO}_{4}{ }^{-3}$

5. PTH - annually, if $<70 \mathrm{ng} /$, no further tests required unless patient goes to Stage 4

- Urinalysis :

1. Urine protein $+/$ - blood

2. Urinary Protein: creatinine

(In presence of proteinuria)

- Current medication including over the counter medicines

- Lifestyle including smoking, diet, weight

\section{Stages of CKD and frequency of monitoring}

Stage 1 -2 CKD:

Stable Stage 3 CKD:

Monitor annually

Progressive Stage 3 CKD: $\quad$ Monitor 6 monthly

(Fall in eGFR of

$>2 \mathrm{ml} / \mathrm{min} / 1.73 \mathrm{~m}^{2}$ over

6 or more months)

Stage 4 - 5CKD:

\section{When to refer}

- Stage 4,5 of CKD - once diagnosed

- Stage 1-3 of CKD - in presence of any of the following:

1. Refractory Hypertension, $>150 / 90 \mathrm{mmHg}$ despite 3 drug treatment

2. Anaemia - Haemoglobin $<11 \mathrm{~g} / \mathrm{dl}$

3. Fall in eGFR of $>2 \mathrm{ml} / \mathrm{min} / 1.73 \mathrm{~m}^{2}$ over 6 or more months (progressive Stage $3 \mathrm{CKD}$ )

4. Rise of Creatinine by $>20 \%$ or fall of eGFR by $>15 \%$ after initiation of ACEI or ARB

5. Unexplained Hypokalaemia or persistent Hyperkalaemia

6. Unexplained Hyponatraemia or Hypernatraemia

7. Hyperphosphataemia , Hypocalcaemia, Hypercalcaemia and high PTH $>70 \mathrm{ng} / \mathrm{l}$ (7.7pmol/l)

8. Proteinuria with Urine Protein: Creatinine $>100 \mathrm{mg} / \mathrm{mmmol}$

- Unexplained haematuria

- Paediatric age group $(0-18$ years $)$ with $\mathrm{CKD}$ - once diagnosed

- Acute deterioration of renal function/ ARF [1.5 fold $\uparrow$ creatinine or $25 \% \downarrow$ of eGFR or Urine output $<0.5 \mathrm{ml} / \mathrm{kg} / \mathrm{hr}$ ]. If eGFR unknown - assume it to be $75 \mathrm{ml} / \mathrm{min} / 1.73 \mathrm{~m}^{2}$ 


\begin{tabular}{|c|c|c|c|c|c|}
\hline \multicolumn{2}{|c|}{$\begin{array}{l}\text { Blood Pressure: Check } \\
\text { U\&Es prior to, and at } 2 \\
\text { weeks from initiation of } \\
\text { ACEI/ARB; at } 2 \text { weeks of } \\
\text { dose adjustment \& at each } \\
\text { follow up }\end{array}$} & \multicolumn{3}{|c|}{$\begin{array}{l}\text { Initiate treatment [with ACEI (1st line) or ARB] when: } \\
\text { 1. BP } 140 / 90 ~ \mathbf{~ m m ~ H g} \text { (Target BP < 130/80 } \mathbf{~ m m ~ H g ) ~} \\
\text { Or } \\
\text { 2. BP 130/80 mmHg - if Diabetic with } \\
\text { Microalbuminuria or Urine Protein: Creatinine }>100 \\
\text { mg/mmol (Target BP } 125 / 75 \mathrm{~mm} \mathbf{H g} \text { ) }\end{array}$} & $\begin{array}{l}\text { Refer to secondary } \\
\text { care if: } \\
\text { Refractory } \\
\text { Hypertension, } \\
\text { >150/90mm } \mathbf{H g} \\
\text { despite } 3 \mathrm{drug} \\
\text { treatment }\end{array}$ \\
\hline \begin{tabular}{l|} 
U \&E s: \\
Check Serum \\
\cline { 2 - 2 } Creatinine, \\
eGFR \& K
\end{tabular} & $.0 \mathrm{mmol} / \mathrm{H}$ & \multicolumn{2}{|c|}{$\begin{array}{l}\text { 1. Ensure fresh } \\
\text { blood sample } \\
\text { 2. Review diet, } \\
\text { medication } \\
\text { (especially } \\
\text { ACEI /ARB) }\end{array}$} & \multicolumn{2}{|c|}{$\begin{array}{l}\text { 1. Stop: Nephrotoxic drugs (e.g. NSAIDS), } \\
\mathrm{K}^{+} \text {sparing diuretics (e.g. Spironolactone, } \\
\text { Amiloride, Triamterene) } \\
\text { 2. Reduce dose of loop diuretics (if possible) } \\
\text { 3. Refer to secondary care if: } \\
\text { Persistent } \uparrow \mathrm{K}^{+}>6.0 \mathrm{mmol} /\end{array}$} \\
\hline & \multicolumn{3}{|c|}{$\begin{array}{l}\text { Any intercurrent illness - } \\
\text { In Stage } 2-5 \mathrm{CKD}\end{array}$} & \multicolumn{2}{|c|}{ Monitor renal function with eGFR } \\
\hline $\begin{array}{l}\text { Haemoglobin: } \\
\text { Rule out other causes }\end{array}$ & & \multicolumn{2}{|c|}{$<11 g /$ dl } & \multicolumn{2}{|c|}{$\begin{array}{l}\text { Start iron }+/ \text { - erythropoietin therapy at } \mathrm{Hb}<11 \mathrm{~g} / \mathrm{dl} \\
\text { Trigger referral and follow up }\end{array}$} \\
\hline \multirow[t]{2}{*}{$\begin{array}{l}\text { Blood Glucose } \\
\text { \& Urinalysis } \\
\text { (If diabetic) }\end{array}$} & \multirow{2}{*}{\multicolumn{2}{|c|}{$\begin{array}{l}\text { Diabetic \& } \\
\text { Microalbuminuria } \\
\text { / proteinuria }\end{array}$}} & \multicolumn{3}{|c|}{$\begin{array}{l}\text { 1. Good glycaemic control }\left(\mathrm{Hb}_{1} \mathrm{C} 6.5-7.5 \%\right) \\
\text { 2. Start ACEI }\left(1^{\text {st }} \text { line }\right) \text { or } A R B ; \text { titrate to full dose irrespect } \\
\text { initial BP [see above] }\end{array}$} \\
\hline & & & \multicolumn{3}{|c|}{$\begin{array}{l}\text { 3. Urinary Protein (or Albumin): Creatinine at least yearly } \\
\text { 4. Refer to secondary care as for patients without Diabetes }\end{array}$} \\
\hline
\end{tabular}

\begin{tabular}{|l|l|l|}
\hline $\begin{array}{l}\text { U rinal ysis: } \\
\text { urinary protein, } \\
\text { blood. }\end{array}$ & $\rightarrow$ Protein 1+ or greater & $\begin{array}{l}\text { 1. Rule out infection } \\
\text { 2. Record (preferably morning sample) urinary albumin: creatinine } \\
\text { 3. Refer to secondary care if: } \\
\text { - Urinary Protein: Creatinine }>100 \mathrm{mg} / \mathrm{mmol} \text { in non diabetics } \\
\text { - Both Proteinuria \& Haematuria } \\
\text { 4. Set target blood pressure as } 125 / 75 \mathrm{~mm} \mathrm{Hg}\end{array}$ \\
\hline
\end{tabular}


summary to aid general practitioners in managing patients with primary care is provided in Figures 1 and 2 . Implementation of guidelines relating to the identification, management and referral will require a considerable change in current practice and additional resources in primary care. However, the cost savings in the long term could be considerable

Competing interests Dr John Bradley has acted as a consultant or advisory board member for Abbott, Amgen, Genzyme and Shire.

\section{REFERENCES}

1 John R, Webb M, Young A, Stevens PE. Unreferred chronic kidney disease: a longitudinal study, Am J Kidney Dis 2004;43:825-35

2 The National Kidney Research Fund. A Position Paper. Available at http://www.nkrf.org.uk/pdfs/news/scharr_report_april2003.pdf (accessed 23 February 2005)

3 Fried LF, Katz R, Sarnak MJ, et al. Kidney function as a predictor of noncardiovascular mortality. J Am Soc Nephrol 2005;12:3728-35

4 Chronic Kidney Disease in Adults: UK Guidelines for Identification, Management and Referral. Available at http://www.renal.org/ CKDguide/full/UKCKDfull.pdf

5 Levey AS, Bosch JP, Lewis JB, Greene T, Rogers N, Roth D. A more accurate method to estimate glomerular filtration rate from serum creatinine: a new prediction equation. Modification of Diet in Renal Disease Study Group. Ann Intern Med 1999;130:461-70
6 Levey AS, Eckardt KU, Tsukamoto Y, et al. Definition and classification of chronic kidney disease: a position statement from Kidney Disease: Improving Global Outcomes (KDIGO). Kidney Int 2005;67:2089-100

7 Renal Association UK. Renal Registry, Seventh Annual Report. Renal Association UK, 2004. Available at http://www.renalreg.com/ Report $\% 202004 /$ Cover_Frame.htm

8 Chiurchiu C, Remuzzi G, Ruggenenti P. Angiotensin-converting enzyme inhibition and renal protection in nondiabetic patients: the data of the meta-analyses. J Am Soc Nephrol 2005;Suppl 1:S58-63

9 Klahr S, Levey AS, Beck GJ, et al. The effects of dietary protein restriction and blood-pressure control on the progression of chronic renal disease. N Engl J Med 1994;330:877-84

10 Investigation into the effects of cholesterol lowering on vascular disease in patients with kidney disease. Available at http:// www.sharpinfo.org/ (accessed 4 September 2005)

11 Cody J, Daly C, Campbell M, et al. Recombinant human erythropoietin for chronic renal failure anaemia in pre-dialysis patients. Cochrane Database Syst Rev 2005;3:CD003266

12 National Kidney Foundation. K/DOQI Clinical Practice Guidelines for Bone Metabolism and Disease in Chronic Kidney Disease. Am J Kidney Dis 2003;42(Suppl 3):S1-201

13 Wauters JP, Lameire N, Davison A, Ritz E. Why patients with progressing kidney disease are referred late to the nephrologist: on causes and proposals for improvement. Nephrol Dial Transplant $2005 ; 20: 490-6$

14 O'Donoghue DJ, Stevens P, Farmer C, Lusignan S De, Walker M. Evaluating the prevalence of chronic kidney disease in the UK using GP computerized records. Renal Association, April 2004 meeting. Available at http://www.renal.org/Abstracts/Apr04abstracts.pdf (accessed 7 October 2004) 